\title{
RANCANG BANGUN ALAT PENDETEKSI ASAP ROKOK DAN NYALA API UNTUK PENANGGULANGAN KESEHATAN DAN KEBAKARAN BERBASIS ARDUINO UNO DAN GSM SIM900A
}

\author{
Dedy Hamdani*, Elda Handayani, Eko Risdianto
}

Program Studi Pendidikan Fisika, Jurusan Pendidikan MIPA Fakultas Keguruan dan Ilmu Pendidikan, Universitas Bengkulu Jalan W.R. Supratman, Kandang Limun, Bengkulu 38123

*Korespondensi ke: dedy.hamdani@unib.ac.id

( Diterima:01 Februari 2019; Direvisi: 9 Februari 2019; Diterbitkan: 01 Maret 2019)

\begin{abstract}
ABSTRAK
Penelitian ini bertujuan untuk membuat alat pendeteksi asap rokok dan nyala api dengan menggunakan sensor MQ-2 dan sensor DFR0076 berbasis Arduino Uno dan GSM SIM900A. Alat pendeteksi asap rokok dan nyala api ini tersusun atas komponen-komponen elektronika, seperti sensor MQ-2 untuk mendeteksi asap rokok, sensor DFR0076 untuk mendeteksi nyala api, Arduino Uno sebagai sistem kontrol dari seluruh rangkaian dan GSM SIM900A untuk mengirimkan informasi ke pengguna. Alat pendeteksi ini dujicoba pada ruangan/kotak yang terbuat dari bahan akrilik dengan dimensi panjang $40 \mathrm{~cm}$, lebar $30 \mathrm{~cm}$, dan tinggi $30 \mathrm{~cm}$. Alat pendeteksi ini dapat mendeteksi asap rokok dan nyala api sampai jarak $25 \mathrm{~cm}$ dari sensor. Jika nilai data digital sensor asap yang terdeteksi lebih besar atau sama dengan $90(\geq 90)$, sistem akan memberikan informasi bahwa terdeteksi asap rokok didalam ruangan. Jika nilai data sensor asap yang terdeteksi kecil dari $90(<90)$, sistem akan memberikan informasi bahwa tidak terdeteksi asap rokok di dalam ruangan. Jika sensor nyala api mendeteksi nilai data digital kecil dari $600(<600)$, sistem akan memberikan informasi bahwa terdeteksi nyala api didalam ruangan. Jika sensor nyala api mendeteksi nilai data digital besar sama 600 ( $\geq 600)$, sistem akan memberikan informasi bahwa tidak terdeteksi nyala api didalam ruangan. Informasi tingkat asap rokok dan nyala api ini kemudian dikirimkan ke pengguna agar pengguna dapat memperoleh informasi dan melakukan tindakan yang diperlukan.
\end{abstract}

Kata kunci: Arduino Uno, GSM SIM900A, Sensor DFR0076, Sensor MQ-2 


\begin{abstract}
The study aims to produce a cigarette smoke and flame device using the MQ-2 sensor and DFR0076 sensors based on Arduino Uno and GSM SIM900A. This device is composed of electronic components, such as the MQ-2 sensor to detect cigarette smoke, DFR0076 sensor to detect flames, Arduino Uno as a control system of all circuits and GSM SIM900A for sending data to users. This device was tested on a room / box made of acrylic with dimensions of $40 \mathrm{~cm}$ long, 30 $\mathrm{cm}$ wide, and $30 \mathrm{~cm}$ high. This device can detect cigarette smoke and flame up to a distance of 25 $\mathrm{cm}$ from the sensors. If the digital data value of the smoke sensor detected is greater or equal to 90, the system will provide information that cigarette smoke is detected in the room. Otherwise, if the digital data value of the smoke sensor detected is smaller than 90, the system will provide information that no smoke is detected in the room. If the flame sensor detects the digital data value smaller than 600, the system will provide information that a flame is detected in the room. Contrarily, if the flame sensor detects the digital data value larger or equal to 600, the system will provide information that there is no flame is detected in the room. Information on the level of cigarette smoke and flame are then sent to the user so that the user can obtain information and take the necessary actions.
\end{abstract}

Keywords: Arduino Uno, GSM SIM900A, DFR0076 Sensor, MQ-2 Sensor

\title{
1. PENDAHULUAN
}

Seiring berkembangnya teknologi yang semakin pesat, banyak manfaat yang dirasakan manusia dalam melakukan aktivitasnya. Manfaat itu diantaranya adalah mengatur keamanan ruangan agar terhindar dari asap rokok dan nyala api. Pengaturan terhadap asap rokok dan nyala api perlu dilakukan untuk menghindari kebakaran ruangan dan menjaga kesehatan, khususnya kesehatan pernapasan yang disebabkan oleh gas beracun yang ada di dalam ruangan tersebut.

Asap rokok sangat berbahaya bagi kesehatan karena mengandung berbagai bahan kimia yang dapat menyebabkan berbagai macam penyakit seperti batuk kronis, kanker paruparu, dan gangguan kesehatan lainnya (Partodiharjo, 2002). Masih banyak manusia yang merokok, meskipun telah mengetahui bahwa asap rokok berbahaya bagi kesehatan. Asap rokok tidak hanya membahayakan kesehatan perokok itu sendiri melainkan juga kesehatan orang lain yang berada disekitarnya, karena senyawa-senyawa yang terkandung dalam asap rokok yang tetap berada di udara terhirup oleh orang lain di sekitar kawasan tersebut.

Mengingat banyaknya penyakit yang ditimbulkan oleh asap rokok maka pemerintah terus berupaya meningkatkan pencegahan larangan merokok di tempat umum. Kebijakan yang dilakukan antara lain membuat kebijakan tentang kawasan bebas asap rokok dan memberi peringatan tertulis tentang larangan merokok yang ditempel pada tempat-tempat umum yang mudah terlihat. Kebijakan ini telah diterapkan di gedung-gedung perkantoran, pendidikan, rumah sakit, dan juga tempat umum lainnya.

Peringatan tertulis ini sering tidak dipatuhi oleh para perokok aktif. Perokok masih sering terlihat merokok ditempat-tempat umum dan terbuka yang mengakibatkan udara menjadi terkontaminasi oleh asap rokok yang sangat berbahaya untuk kesehatan tubuh manusia. Setelah selesai merokok, perokok biasanya langsung membuang puntung rokok tanpa mematikan api rokok terlebih dahulu. Sisa puntung rokok yang masih menyala dan 
dibuang sembarangan dapat menjadi salah satu sumber terjadinya kebakaran yang sangat merugikan.

Berdasarkan permasalahan tersebut, perlu adanya perangkat otomatis yang dapat mendeteksi asap rokok dan nyala api di suatu ruangan. Asap rokok dan nyala api dapat dideteksi dengan piranti elektronika yang disebut dengan sensor. Ada banyak jenis sensor saat ini seperti sensor MQ-2 dan sensor DFR0076. Sensor MQ-2 dapat digunakan untuk mendeteksi kebocoran gas dan asap rokok (Hanwei Eletronics, 2011). Sensor MQ-2 merupakan sensor yang sensitif terhadap gas metana, butana, LPG, dan asap rokok (Kadir, 2016). Beberapa penelitian sebelumnya telah menggunakan sensor MQ-2 untuk aplikasi mendeteksi kebocoran gas LPG (Christian \& Komar, 2013; Rifa'i, 2016) dan asap rokok (Sumajouw, Najoan, \& Sompie, 2015; Mandarani \& Ariani, 2016).

Sensor DFR0076 adalah sensor yang dapat digunakan untuk mendeteksi nyala api. (DFROBOT, 2016). Sensor DFR0076 mampu menangkap cahaya dengan panjang gelombang cahaya rata-rata $940 \mathrm{~nm}$ dengan lebar bandwidth spektrum panjang gelombang $760 \mathrm{~nm}-1100 \mathrm{~nm}$ sehingga sangat cocok digunakan untuk mendeteksi adanya nyala api di dekat permukaan sensor (Utomo \& Saputra, 2016).

Informasi tentang asap rokok dan nyala api di suatu ruangan perlu dikirim ke pengguna melalui layanan short message secvice (SMS) agar pengguna dapat melakukan tindakan pencegahan terhadap asap rokok dan nyala api yang terjadi. GSM SIM900A merupakan salah perangkat yang dapat digunakan untuk berkomunikasi kepada pengguna melalui layanan SMS (Atrim Electronics, 2014). Pada penelitian ini, telah dibuat alat pendeteksi asap rokok dan nyala api dan diujicobakan dalam ruangan/kotak yang terbuat dari bahan akrilik dengan dimensi panjang $40 \mathrm{~cm}$, lebar $30 \mathrm{~cm}$, dan tinggi $30 \mathrm{~cm}$. Akrilik ini merupakan bahan yang ringan dan transparan, sehingga alat-alat elektronik penyusun alat pendeteksi asap rokok dan kebakaran terlihat dengan jelas.

\section{METODE PENELITIAN}

Sistem alat pendeteksi asap rokok dan nyala api terdiri dari dua perangkat, perangkat keras (hardware) dan perangkat lunak (software). Sistem perangkat keras dapat dilihat pada gambar 1. Sistem terdiri dari input berupa sensor, pengontrol berupa Arduino Uno dan GSM SIM900A dan output berupa LCD, kipas, buzzer, Led dan handphone untuk mengirim data ke pengguna.

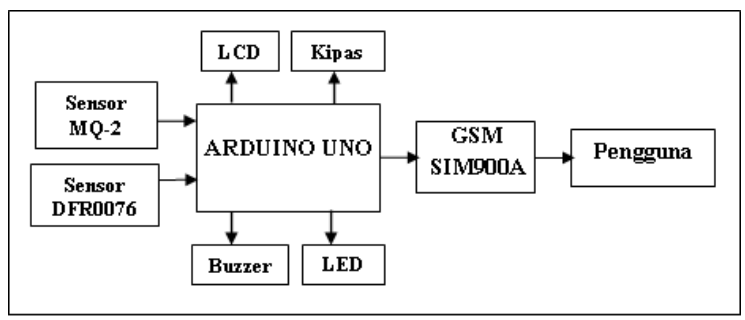

Gambar 1 Diagram blok sistem alat pendeteksi asap rokok dan nyala api

Sensor yang digunakan ada dua, yaitu sensor MQ-2 yang berfungsi untuk mendeteksi keberadaan asap rokok dan sensor DFR0076 yang berfungsi untuk mendeteksi sumber nyala api. Arduino Uno berfungsi sebagai sistem pengontrol dari semua rangkaian termasuk berkomunikasi dengan GSM SIM 900A. GSM SIM 900A berfungsi sebagai modul yang digunakan untuk melakukan pengiriman SMS kepada pengguna. 
Handphone digunakan oleh pengguna sebagai alat komunikasi untuk menerima SMS dari modul GSM SIM900A bila terdeteksi adanya asap rokok dan api yang menyala di sekitar sensor. LCD digunakan untuk menampilkan kadar asap rokok dan nyala api yang terdeteksi. Kipas (fan) berfungsi untuk menguraikan asap rokok yang terdeteksi dengan kontrol SMS. Buzzer berfungsi sebagai output untuk indikator bunyi pada saat terdeteksi asap rokok dan nyala api. LED (merah dan hijau) digunakan sebagai output untuk indikator peringatan pada saat terdeteksi asap rokok dan nyala api.

Perancangan sistem perangkat lunak atau diagram alir (flowchart) alat pendeteksi asap rokok dan nyala api ditunjukkan pada gambar 2 .

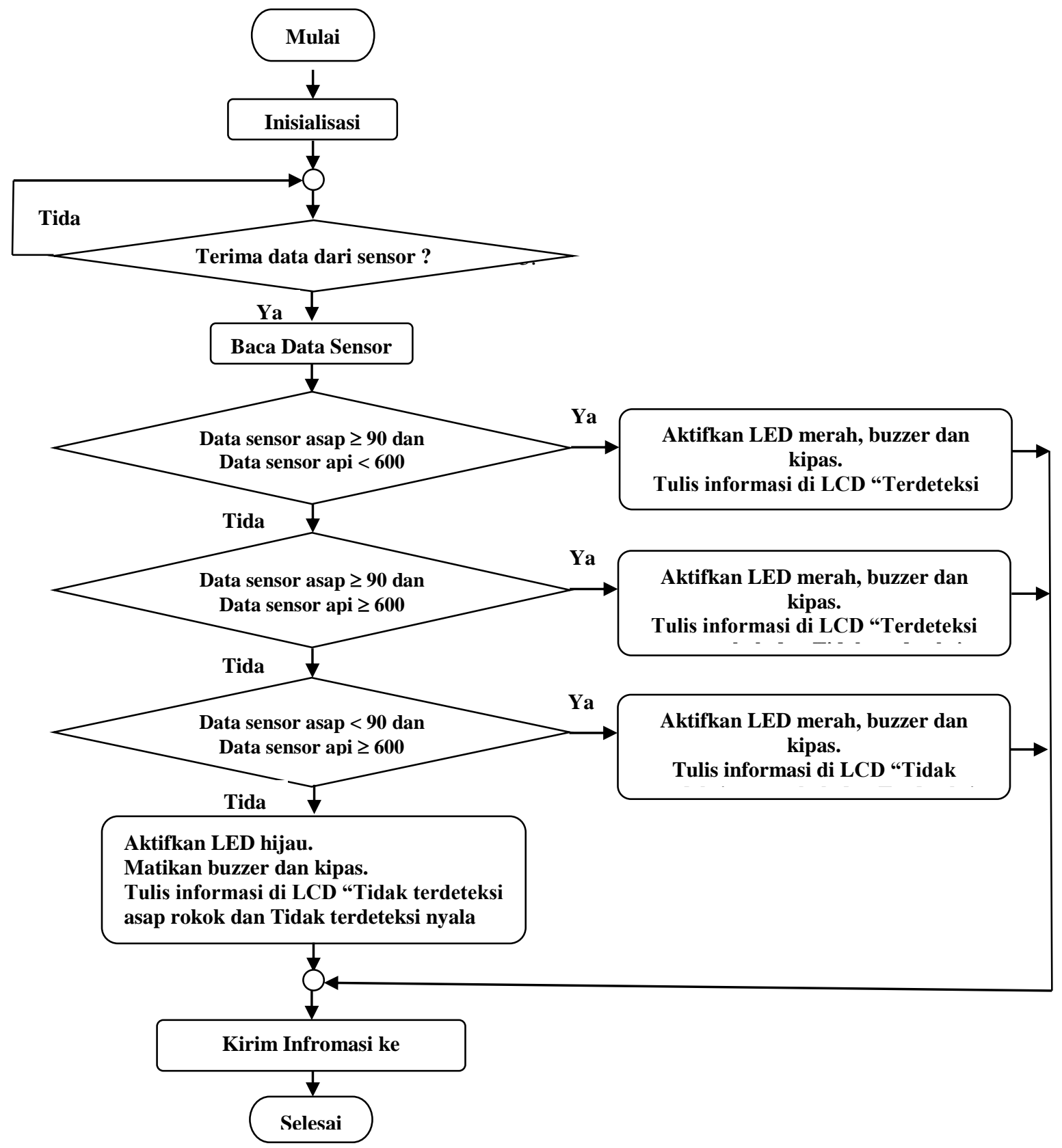

Gambar 2 Diagram alir alat pendeteksi asap rokok dan nyala api 
Sistem alat pendeteksi asap rokok dan nyala api dimulai dengan menginisialisasi keseluruhan pin yang dibutuhkan. Alat akan menunggu apakah sensor mendeteksi asap rokok dan nyala api. Jika sensor mendeteksi, maka alat akan membaca data sensor, kemudian akan mengecek kondisi.

Jika nilai data sensor asap yang terdeteksi $\geq 90$ dan sensor api yang terdeteksi $<600$, sistem akan menuliskan informasi di LCD "Terdeteksi asap rokok dan Terdeteksi nyala api”. Sistem kemudian akan menghidupkan LED merah, mengaktifkan buzzer dan kipas kemudian mengirim informasi ke pengguna. Kondisi ini berarti bahwa ruangan berada dalam keadaan waspada asap rokok dan nyala api. Jika nilai data sensor asap yang terdeteksi $\geq 90$ dan sensor api yang terdeteksi $\geq 600$, sistem akan menuliskan informasi di LCD “Terdeteksi asap rokok dan Tidak terdeteksi nyala api”. Sistem akan mengaktifkan LED merah, buzzer dan kipas kemudian mengirim informasi ke pengguna. Kondisi ini berarti bahwa ruangan berada dalam keadaan waspada asap rokok.

Jika nilai data sensor asap yang terdeteksi $<90$ dan sensor api yang terdeteksi $<600$, sistem akan menuliskan informasi di LCD "Tidak terdeteksi asap rokok dan Terdeteksi nyala api". LED merah, buzzer dan kipas akan diaktifkan dan kemudian sistem mengirim informasi ke pengguna. Kondisi ini berarti bahwa ruangan berada dalam keadaan waspada nyala api. Jika nilai data sensor asap yang terdeteksi $<90$ dan sensor api yang terdeteksi $\geq 600$, sistem akan menuliskan informasi di LCD "Tidak terdeteksi asap rokok dan Tidak terdeteksi nyala api". Sistem kemudian akan menghidupkan LED hijau, mematikan buzzer dan kipas kemudian sistem mengirim informasi ke pengguna. Kondisi ini berarti bahwa ruangan berada dalam keadaan aman dari asap rokok dan nyala api.

Perancangan perangkat keras alat pendeteksi asap rokok dan nyala api secara lengkap dapat dilihat pada gambar 3. Alat pendeteksi ini dujicoba pada ruangan/kotak yang terbuat dari bahan akrilik dengan dimensi panjang $40 \mathrm{~cm}$, lebar $30 \mathrm{~cm}$, dan tinggi $30 \mathrm{~cm}$. Arduino Uno, Sensor MQ-2 dan sensor DFR0076 berada di sisi sebelah kiri kotak. GSM SIM 900A, Relay dan Kipas terletak di sisi sebelah kanan kotak. LCD dan LED diletakkan di bagian depan kotak, menghadap keluar bidang gambar. Sumber asap rokok dan nyala api diletakkan di dalam kotak dan posisinya terhadap sensor dapat diatur.

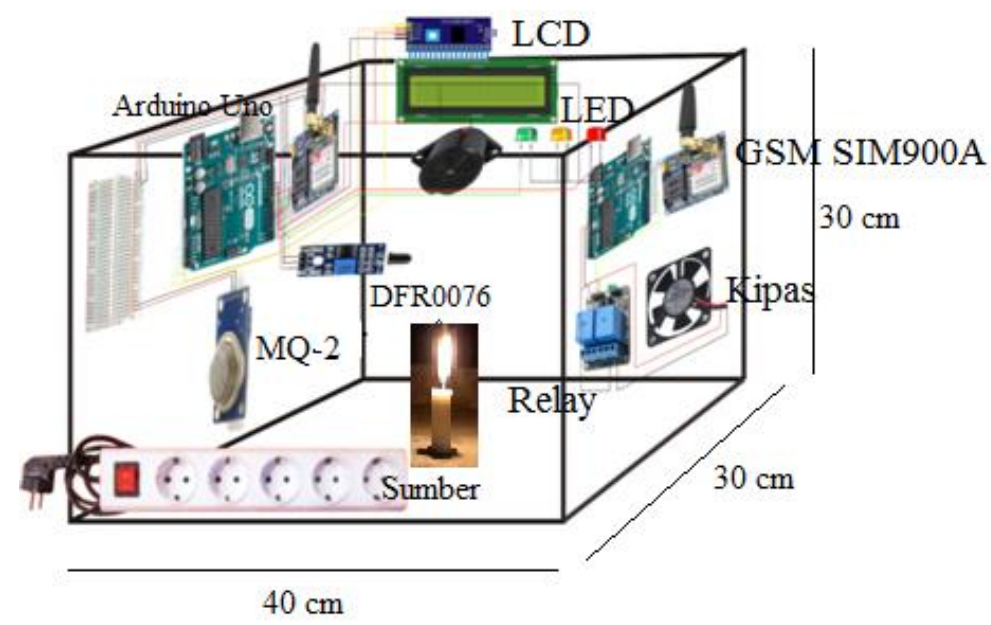

Gambar 3 Rancangan perangkat keras alat pendeteksi asap rokok dan nyala api 


\section{HASIL DAN DISKUSI}

\subsection{Pengujian Sistem Sensor MQ-2}

Sensor MQ-2 mendeteksi keberadaan gas-gas yang dianggap mewakili asap rokok, yaitu gas hidrogen dan metana. Jika sensor mendeteksi keberadaan asap rokok di udara dengan tingkat konsentrasi tertentu, maka sensor akan menganggap bahwa ada asap rokok di udara. Ketika sensor MQ-2 mendeteksi keberadaan asap rokok tersebut maka resistansi elektrik sensor akan turun dan menyebakan tegangan yang dihasilkan oleh output sensor akan semakin besar. Keluaran sensor yang berupa resistansi analog dapat dikonversi menjadi tegangan dengan menambahkan sebuah resistor. Hasil bacaan sensor dibaca oleh pin ADC (analog to digital converter) pada Arduino Uno.

Pengujian sensor MQ-2 dilakukan di dalam kotak dengan menggunakan asap rokok yang berasal dari puntung rokok sebagai sumber asap rokok. Jarak sumber asap rokok terhadap sensor divarasikan dengan jarak tertentu untuk mengetahui apakah sensor MQ-2 masih dapat mendeteksi sumber asap rokok. Data pegujian sensor MQ-2 terdapat pada tabel $1 \mathrm{di}$ bawah ini.

Tabel 1 Data Pengujian Sensor MQ-2

\begin{tabular}{ccc}
\hline $\begin{array}{c}\text { Jarak sumber asap } \\
\text { dengan sensor }(\mathbf{c m})\end{array}$ & $\begin{array}{c}\text { Data Sensor } \\
\text { (bilangan digital) }\end{array}$ & Keterangan \\
\hline 5 & 99 & Terdeteksi \\
10 & 95 & Terdeteksi \\
15 & 77 & Terdeteksi \\
20 & 70 & Terdeteksi \\
25 & 65 & Terdeteksi \\
\hline
\end{tabular}

Berdasarkan tabel 1 diatas terlihat bahwa sensor MQ-2 bisa mendeteksi sumber asap rokok hingga jarak $25 \mathrm{~cm}$. Semakin jauh jarak sumber asap rokok dengan sensor MQ-2 maka semakin rendah kadar asap rokok (nilai bilangan digital) yang terbaca. Begitu juga sebaliknya, semakin dekat sumber asap rokok dengan sensor MQ-2 maka kadar asap rokok yang terbaca oleh sensor semakin tinggi.

Jika sensor mendeteksi kadar asap rokok di atas atau sama dengan $90(\geq 90)$ maka LED merah akan diaktifkan, kipas diaktifkan, buzzer sebagai alarm juga akan berbunyi dan sistem akan mengirimkan informasi berupa teks peringatan kepada pengguna bahwa di dalam ruangan terdeteksi asap rokok. Keadaan ini berarti bahwa ruangan berada dalam keadaan waspada. Jika sensor mendeteksi kadar asap rokok di bawah $90(<90)$ maka LED hijau akan diaktifkan, kipas dan buzzer sebagai alarm akan dinon-aktifkan, dan sistem mengirimkan informasi berupa teks peringatan kepada pengguna bahwa tidak terdeteksi asap rokok di dalam ruangan. Kondisi ini berarti bahwa ruangan berada dalam keadaan aman dari asap rokok.

\subsection{Pengujian Sistem Sensor DFR0076}

Pada sensor DFR0076 terdapat sebuah tranduser yang digunakan untuk mendeteksi penyerapan cahaya pada panjang gelombang tertentu dan dapat membedakan antara spektrum cahaya pada api dengan spektrum cahaya lainnya. Sensor ini sudah dilengkapi dengan komparator (pembanding) nilai spektrum gelombang cahaya infa merah yang berasal dari api. Dari pancaran cahaya tersebut akan mengubah nilai hambatan pada sensor, jika terdapat nyala api maka nilai hambatan pada sensor akan mengalami 
penurunan yang menyebabkan arus masuk ke komparator sehingga terdapat arus yang keluar menuju output sensor.

Dalam pengujian sensor DFR0076, sumber api yang digunakan adalah api lilin sebagai sumber nyala api. Sumber nyala api diletakkan didalam kotak. Jarak sumber nyala api terhadap sensor DFR0076 divariasikan dengan jarak tertentu untuk mengetahui apakah sensor dapat mendeteksi nyala api. Data pengujian sensor dapat dilihat pada tabel 2.

Tabel 2 Data Pengujian Sensor DFR0076

\begin{tabular}{cccc}
\hline $\begin{array}{c}\text { Jarak api dengan } \\
\text { sensor }(\mathbf{c m})\end{array}$ & $\begin{array}{c}\text { Nilai digital } \\
\text { pada LCD }\end{array}$ & Tegangan $(\mathbf{V})$ & Keterangan \\
\hline 5 & 40 & 0,12 & Terdeteksi \\
10 & 43 & 0,17 & Terdeteksi \\
15 & 49 & 0,23 & Terdeteksi \\
20 & 57 & 1,03 & Terdeteksi \\
25 & 62 & 1,71 & Terdeteksi \\
\hline
\end{tabular}

Tabel 2 memperlihatkan bahwa sensor DFR0076 dapat mendeteksi nyala api sampai jarak $25 \mathrm{~cm}$. Semakin jauh sumber nyala api dari sensor maka semakin besar nilai digital sensor yang dihasilkan dan tegangan yang dihasilkan oleh sensor juga semakin besar. Semakin dekat sumber nyala api dari sensor maka nilai digital sensor yang dihasilkan semakin kecil dan tegangan yang dihasilkan oleh sensor juga semakin kecil.

Apabila sensor DFR0076 mendeteksi nyala api dengan nilai besar atau sama $600(\geq 600)$ maka sistem akan menghidupkan LED hijau, mematikan buzzer dan sistem akan mengirimkan informasi ke penggguna bahwa tidak terdeteksi nyala api dalam ruangan. Kondisi ini berarti bahwa ruangan berada dalam keadaan aman dari nyala api. Jika sensor membaca nyala api kurang dari $600(<600)$, maka LED merah akan aktif, buzzer akan berbunyi akan sistem akan mengirimkan informasi ke penggguna bahwa terdapat nyala api di di dalam ruangan.

\subsection{Pengujian Pengiriman Informasi Asap Rokok dan Kebakaran}

Pengiriman data kepada pengguna dilakukan oleh modul GSM SIM900A yang terhubung ke Arduino Uno melalui pin RX dan TX. Modul ini bisa menerima data yang terbaca oleh Arduino Uno berdasarkan nilai sensor. Nilai sensor yang terbaca pada Arduino Uno akan dikirimkan oleh Modul GSM SIM900A kepada nomor handphone pengguna yang sudah terkoneksi pada SIM tersebut.

Pin output sensor asap rokok dihubungkan pada pin A0 pada Arduino dan pin output sensor nyala api dihubungkan pada pin A1 pada Arduino. Kedua sensor ini dipasang pada pin analog pada Arduino untuk dikonversi ke nilai ADC dengan rentang 0-1023. Berdasarkan nilai yang terbaca tersebut akan diolah menjadi sebuah indikator. Data yang terbaca oleh sensor juga ditampilkan melalui LCD agar pengguna bisa mengetahui data sensor tersebut. Gambar 4 memperlihatkan bentuk pengiriman informasi yang dikirim modul GSM SIM900A kepada pengguna. 


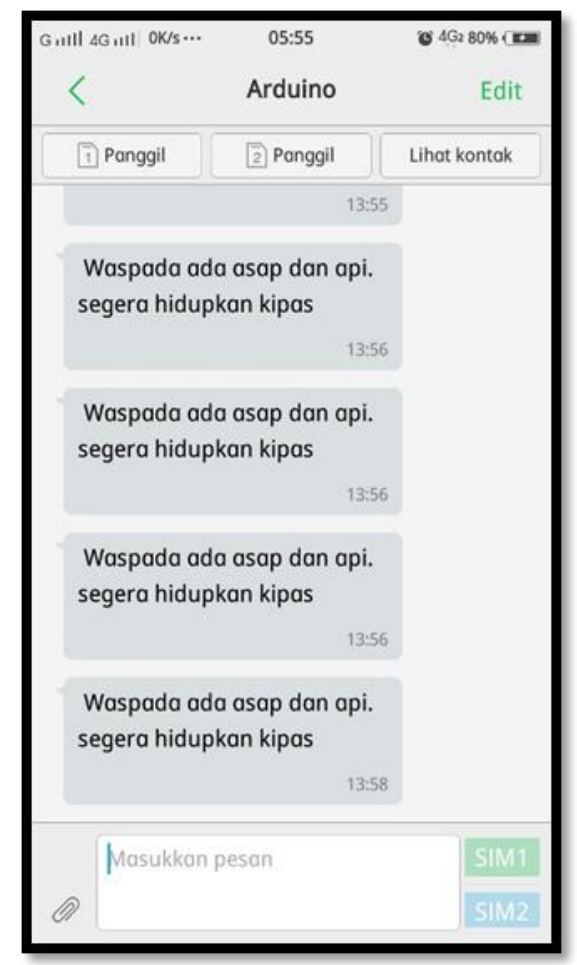

Gambar 4 Bentuk Informasi yang dikirim Modul GSM SIM900A

\subsection{Pengujian Sistem Rangkaian Kontrol Kipas}

Rangkaian kontrol kipas terdiri dari beberapa komponen elektronik yaitu Modul GSM SIM900A, Arduino, relay 5V DC, kipas, dan Arduino Uno. Pada rangkaian tersebut kipas dihubungkan dengan relay yang berfungsi sebagai saklar otomatis kipas. Pemasangan relay yang dihubungkan dengan baterai bertujuan untuk menambah tegangan kipas sehingga putaran kipas lebih kencang. Pin input relay dihubungkan dengan pin digital 9 pada Arduino Uno yang sudah diprogram untuk menghidupkan dan mematikan kipas berdasarkan perintah yang terbaca oleh modul GSM SIM900A. Ketika ada perintah KIPAS ON dari pengguna yang dikirimkan melalui modul GSM SIM900A maka relay akan berlogika 1 atau relay berada dalam kondisi ON dan kipas akan aktif. Begitu juga sebaliknya jika diberikan perintah KIPAS OFF, maka kipas akan dimatikan. Gambar 5 memperlihatkan tampilan perintah ON/OFF yang dikontrol oleh pengguna melalaui handphone. 


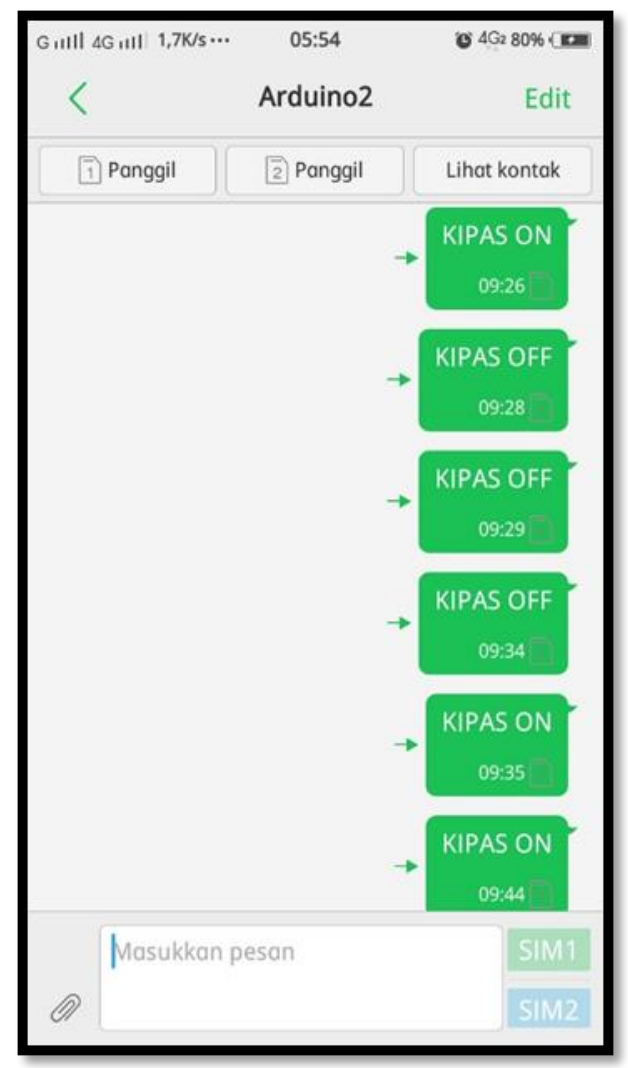

Gambar 5 Kontrol kipas dengan handphone

\section{KESIMPULAN}

Telah dibuat alat pendeteksi asap rokok dan nyala api dengan menggunakan sensor MQ-2 dan DFR0076 berbasis Arduino Uno dan GSM SIM900A. Alat ini diujicobakan pada ruangan/kotak yang berdimensi panjang $40 \mathrm{~cm}$, lebar $30 \mathrm{~cm}$, dan tinggi $30 \mathrm{~cm}$. Alat pendeteksi ini berfungsi sebagaimana mestinya sesuai dengan rancangan yang telah direncanakan dan sesuai harapan. Sensor MQ-2 dapat mendeteksi kadar asap rokok hingga jarak $25 \mathrm{~cm}$ dari sumber asap rokok. Semakin dekat sumber asap rokok maka nilai kadar asap rokok yang terdeteksi juga semakin besar yang berarti ruangan tidak sehat. Sensor DFR0076 juga dapat mendeteksi nyala api hingga jarak $25 \mathrm{~cm}$ dari sumber nyala api. Semakin dekat sumber nyala api maka nilai kadar nyala api terdeteksi juga semakin kecil yang berarti potensi kebakaran semakin besar. Alat kemudian akan mengirimkan informasi kepada pengguna agar pengguna dapat memperoleh informasi dan melakukan tindakan yang diperlukan.

\section{DAFTAR PUSTAKA}

1. Atrim Electronics, GSM Shield using SIMCOMM (SIM900A) manual. (2014).Christian, J., \& Komar, N. Prototipe Sistem Pendeteksi Kebocoran Gas LPG

2. Menggunakan Sensor Gas MQ2, Board Arduino Duemilanove, Buzzer, dan Arduino GSM Shield pada PT. Alfa Retailindo (Carrefour Pasar Minggu). Jurnal TICOM, 2(1), 58-64 (2013). 
3. DFROBOT. Flame Sensor SKU: DFR0076. Diambil dari https://www.dfrobot.com/wiki/index.php/Flame_sensor_(SKU:_DFR0076) . Diakses tanggal 28 Februari 2019. (2016).

4. Hanwei Eletronics Co.Ltd Technical Data Mq-2 Gas Sensor. (2011).

5. Kadir, A. Simulasi Arduino. (Elex Media Komputindo, Jakarta, 2016).

6. Mandarani, P., \& Ariani, R. Perancangan Sistem Deteksi Asap Rokok Menggunakan Layanan Short Massage Service (SMS) Alert Berbasis Arduino. Jurnal Teknologi Informatika, 4 (2), 66-75 (2016).

7. Partodiharjo, S. Kenali Narkoba dan Musuhi Penyalahgunaanya. (Erlangga, Jakarta, 2005).

8. Rifa'i, A. F. Sistem Pendeteksi dan Monitoring Kebocoran Gas (Liquefied Petrolum Gas) Berbasis Internet of Things. JISKA, 1 (1), 5-13 (2016).

9. Sumajouw, D. F., Najoan, M. E., \& Sompie, S. R. Perancangan Sistem Keamanan Rumah Tinggal Terkendali Jarak Jauh. E-journal Teknik Elektro dan Komputer, 4 (3), 44-53 (2015).

10. Utomo, B. T., \& Saputra, D. S. Simulasi Sistem Pendeteksi Polusi Ruangan Menggunakan Sensor Asap dengan Pemberitahuan Melalui SMS (Short Massage Service) dan Alarm Berbasis Arduino. Jurnal Ilmiah Teknologi dan Informasi Asia, 10 (1), 56-57 (2016). 